\title{
Evaluación clínica, endoscópica y citológica de las vías aéreas de equinos de tracción
}

\section{Clinical, endoscopic and cytologic evaluation of airways of horses pulling}

\author{
Vargas Menjura Hamith Leandro ${ }^{1}$, Castro Beck Carlos A. ${ }^{2}$ y \\ Jaramillo H. Dumar Alexander ${ }^{3}$ \\ ${ }^{1} \mathrm{MVZ}$, Teniente de la Policía Nacional de Colombia; ${ }^{3} \mathrm{MV}, \mathrm{MSc}, \mathrm{PhD}$. Profesor \\ Asociado, Director Hospital de Clínica Veterinaria de la Universidad Federal do Rio \\ Grande do Sul y ${ }^{3} \mathrm{MVZ}$, Esp., (c)MSc. Líder Grupo de Investigación en \\ Farmacología Experimental y Medicina Interna - Élite, Profesor Clínica de \\ Grandes Animales, Universidad de los Llanos \\ dumar.jaramillo@unillanos.eu.co
}

Recibido 12 de Diciembre 2014, Aceptado 26 de Septiembre 2015

\section{RESUMEN}

Las afecciones del sistema respiratorio, tienen un papel fundamental en la disminución del desempeño atlético de los equinos, los exámenes como la broncoscopia que se realiza con endoscopio flexible, y citológicos (lavados transtraqueales y broncoalveolares), han sido usados como métodos de diagnóstico en animales con sintomatología de deficiencia respiratoria. Durante los últimos años su implementación ha tenido un notable aumento debido a su eficacia en los dictámenes, lo que se traduce, en disminución de tiempo y costos de tratamientos. En el presente estudio, se tomaron muestras a diez equinos $\sin$ raza definida, con edades entre los 7 y 15 años, provenientes de la clínica de grandes animales del hospital veterinario de la Universidad Federal do Rio Grande do Sul (UFRGS), los cuales nueve eran usados para la tracción de carrosa en la zona metropolitana y uno para carreras hípicas de Porto Alegre. A todos los animales se les realizó examen clínico general, enfatizando en las vías respiratorias, se realizaron cuatro endoscopias y se colectaron diez muestras de secreciones traqueales por medio de lavado y aspirado percutáneo. La suspensión celular de los lavados fue centrifugada, para realizar extendidos sobre láminas, que fueron coloreados por el método panóptico rápido (tinción diferencial), que 
permite la observación de células sanguíneas. Se realizó estadística descriptiva de las variables analizadas. Los animales presentaron frecuencia cardiaca $39.2 \pm$ 1.44 latidos por minuto $(\mathrm{Ipm})$, frecuencia respiratoria $19.7 \pm 2.37$ respiraciones por minuto (rpm), temperatura $38.25 \pm 0.08^{\circ} \mathrm{C}$, hematocrito $34.7 \pm 1.09 \%$, recuento de eritrocitos $7.25 \pm 0.27 \times 106 / \mathrm{ml}$, hemoglobina $11.34 \pm 0.042 \mathrm{~g} / \mathrm{dll}$, volumen corpuscular medio $49.85 \pm 0.96$ fentolitros (fl), concentración de hemoglobina corpuscular media $32.77 \pm 0.45 \mathrm{~g} / \mathrm{dl}$, plaquetas $183.8 \pm 10.98 \times 10^{3} / \mathrm{ml}$, proteínas plasmáticas totales $7.3 \pm 0.13 \mathrm{~g} / \mathrm{dl}$, leucocitos totales $9.880 \pm 470 / \mathrm{ml}$, neutrófilos $5.910 \pm 560 / \mathrm{ml}$, eosinófilos $359.2 \pm 70.8 / \mathrm{ml}$, linfocitos $3.420 \pm 420 / \mathrm{ml}$ y monocitos $339.8 \pm 50.12 / \mathrm{ml}$. En la citología del lavado traqueal se determinaron los porcentajes de células epiteliales en $42.3 \pm 9.35$, linfocitos $3.3 \pm 1.13$, macrófagos $20.1 \pm 5.35$, neutrófilos $26.4 \pm 8.37$ y eosinófilos $2.7 \pm 1.78$. Finalmente los resultados del examen endoscópico en los equinos fueron: 1) cantidad normal de moco y ausencia de bacterias (sanos), 2) aumento de la producción de moco y de bacterias en el medio extracelular y superficie de células escamosas, 3) degeneración celular y picnosis, 4) fagocitos y restos celulares, y 5) fungosis (hongos conídeos) en el fondo extracelular y fagocitosis, observándose cristales de hematoidina y procesos apoptóticos. Se concluye que la endoscopia y la citología del lavado traqueal son herramientas fundamentales para el diagnóstico de las enfermedades respiratorias, ya que permiten la identificación de trastornos funcionales, vislumbrando el tipo celular predominante, que ocasiona el proceso inflamatorio existente.

Palabras clave: Broncoscopia, sistema respiratorio, lavado transtraqueal.

\section{ABSTRACT}

Disorders of the respiratory system have a key role in reducing the athletic performance of horses, tests such as bronchoscopy that is performed with flexible endoscope, and cytological (tracheal washings) have been used as diagnostic methods in animals with symptoms of respiratory failure. In recent years its implementation has had a significant increase due to its effectiveness in the opinions, resulting in decreased treatment time and costs. In this study, samples 
were taken to ten horses without defined breed, aged between 7 and 15 years, from clinical large animal veterinary hospital of the Federal University of Rio Grande do Sul (UFRGS), which nine were used for pulling in the metropolitan area and one for horse racing in Porto Alegre. All animals underwent clinical examination, emphasizing airway four endoscopies were performed and ten samples of tracheal secretions were collected by washing and percutaneous aspiration. The washed cell suspension was centrifuged for extended on slides, which were stained by the method of panoptical fast (differential staining), which allows the observation of blood cells. Descriptive statistics of the variables analyzed was performed. The animals showed heart rate $39.2 \pm 1.44$ beats per minute $(\mathrm{bpm})$, respiratory rate $19.7 \pm 2.37$ breaths per minute (rpm), temperature $38.25 \pm 0.08^{\circ} \mathrm{C}$, hematocrit $34.7 \pm 1.09 \%$, erythrocyte count $7.25 \pm 0.27 \times 10^{6} / \mathrm{ml}$, hemoglobin $11.34 \pm 0.042 \mathrm{~g} / \mathrm{dl}$, mean corpuscular volume average $49.85 \pm 0.96$ fentoliters (fl), 32 corpuscular hemoglobin concentration $77 \pm 0.45 \mathrm{~g} / \mathrm{dl}$, platelets $183.8 \pm 10.98 \times 10^{3} / \mathrm{ml}$, total plasma proteins $7.3 \pm 0.13 \mathrm{~g} / \mathrm{dl}$, total leukocytes 9,880 $\pm 470 / \mathrm{ml}$, neutrophils $5,910 \pm 560 / \mathrm{ml}$, eosinophils $359.2 \pm 70.8 / \mathrm{ml}$, lymphocytes $3,420 \pm 420 / \mathrm{ml}$ and monocytes $339.8 \pm 50.12 / \mathrm{ml}$. In tracheal wash cytology were determined the percentages of epithelial cells in $42.3 \pm 9.35$, lymphocytes $3.3 \pm$ 1.13, macrophages $20.1 \pm 5.35$, neutrophils $26.4 \pm 8.37$ and eosinophils $2.7 \pm 1.78$. Finally the results of endoscopic examination in horses were: 1) normal amount of mucus and absence of bacteria (healthy), 2) increased production of mucus and bacteria in the extracellular medium and squamous cell surface, 3) cellular degeneration and picnosis, 4) phagocytes and cell debris, and 5) fungus in the extracellular background and phagocytosis, observed Hematoidin crystals and apoptotic processes. It is concluded that endoscopy and tracheal wash cytology are essential tools for the diagnosis of respiratory diseases, allowing the identification of functional disorders, glimpsing the predominant cell type, which causes the existing inflammatory process.

Keywords: Bronchoscopy, respiratory system, transtracheal wash. 


\section{RESUMO}

Doenças do sistema respiratório, têm um papel fundamental na redução do desempenho atlético de cavalos, exames como broncoscopia, que é realizada com endoscópio flexível e citológico (lavagens traqueais) têm sido usados como métodos de diagnóstico em animais com sintomas de insuficiência respiratória. Nos últimos anos, a sua implementação tem tido um aumento significativo devido à sua eficácia nas pareceres, resultando em diminuição do tempo de tratamento e custos. Neste estudo, foram colhidas amostras para dez cavalos, sem raça definida, com idade entre 7 e 15 anos, de clínica veterinária de animais grande hospital da Universidade Federal do Rio Grande do Sul (UFRGS), que foram nove usado para puxar carrosa na região metropolitana e outro para a corrida de cavalos em Porto Alegre. Todos os animais foram submetidos a exame clínico, enfatizando vias aéreas, quatro endoscopias foram realizadas e dez amostras de secreção traqueal foram recolhidos por lavagem e aspiração percutânea. A suspensão de células foi centrifugada durante lavada estendida em lâminas, as quais foram coloridas pelo método panóptico rápida (coloração diferencial), que permite a observação de células sanguíneas. A estatística descritiva das variáveis analisadas foi realizada. Os animais apresentaram $39.2 \pm 1.44$ freqüência cardíaca batimentos por minuto (bpm), freqüência respiratória $19.7 \pm 2.37$ respirações por minuto (rpm), a temperatura $38.25 \pm 0.08^{\circ} \mathrm{C}$, hematócrito $34.7 \pm 1.09 \%$, contagem de eritrócitos $7.25 \pm 0.27 \times 10^{6} / \mathrm{ml}$ ), hemoglobina $11.34 \pm 0.042 \mathrm{~g} / \mathrm{dll}$, volume corpuscular média $49.85 \pm 0.96$ fentolitros (fl), concentração de hemoglobina corpuscular $32.77 \pm 0.45 \mathrm{~g} / \mathrm{dl}$, plaquetas $183.8 \pm 10.98 \times 10^{3} / \mathrm{ml}$, proteínas plasmáticas totais de $7.3 \pm 0.13 \mathrm{~g} / \mathrm{dl}$, leucócitos totais $9,880 \pm 470 / \mathrm{ml}$, neutrófilos $5,910 \pm 560 / \mathrm{ml}$, eosinófilos $359.2 \pm 70.8 / \mathrm{ml}$, linfocitos $3,420 \pm 420 / \mathrm{ml}$ e monócitos $339.8 \pm 50.12 / \mathrm{ml}$. Em citologia do lavagem traqueal foram determinados percentagens de células epiteliais em $42.3 \pm 9.35$, linfocitos $3.3 \pm 1.13$, macrófagos $20.1 \pm 5.35$, neutrófilos $26.4 \pm 8.37$ e eosinófilos $2.7 \pm 1.78$. Finalmente, os resultados do exame endoscópico em cavalos foram: 1) a quantidade normal de muco e ausência de bactérias (saudável), 2) um aumento da produção de muco e bactérias na do meio extracelular e superficie de célula 
escamosa, 3) degeneração celular e picnose 4), fagócitos e detritos celulares, e 5) fungosis (conídeos do fungos) no fundo extracelular e fagocitose observados cristais hematoidin e processos apoptóticos. Conclui-se que a endoscopia e citologia lavagem traqueal são ferramentas essenciais para o diagnóstico de doenças respiratórias, permitindo a identificação de distúrbios funcionais, vislumbrando o tipo de célula predominante, o que faz com que o processo inflamatório existente.

Palavras-chave: Broncoscopia, sistema respiratório, lavagem transtraqueal.

\section{INTRODUCCIÓN}

El manejo clínico de equinos, principalmente los destinados para competencia, en deportes como corrida, hipismo, polo, rodeo o coleo, entre otras, o aquellos que son sometidos a extensas jornadas de trabajo, en la ciudad y zonas rurales, ha sido un reto para los médicos veterinarios, debido a la gran dependencia que el hombre ha impuesto sobre esta especie, alta incidencia de patologías y elevado costo de los tratamientos. En este mismo sentido, los trastornos del sistema respiratorio ocupan el segundo lugar en la limitación del desempeño atlético de los equinos, siendo solo superados por los del sistema musculo esquelético (Reed y Bayly, 2010). Estas patologías respiratorias producen grandes pérdidas económicas relacionadas con la interrupción del entrenamiento de los animales (Moran et al., 2003). Al respecto, Davidson y Martin, (2003) reportaron que estas enfermedades fueron inidentificadas en un $42 \%$ de los caballos atletas que presentaban disminución de su desempeño.

La endoscopia se ha utilizado para evaluar el tracto respiratorio de equinos, siendo una herramienta muy útil, puesto que la clasificación de los signos respiratorios junto con los hallazgos endoscópicos genera información importante para el diagnóstico de enfermedades respiratorias (Viel y Hewson, 2004). Así mismo, otros exámenes complementarios pueden llevarse a cabo para detectar patologías relacionadas con el tracto respiratorio inferior, tales como la colecta de secreciones, que pueden ser obtenidas por tres métodos: lavado trans traqueal, 
aspirado traqueal, y lavado bronco alveolar, donde el primero es el más económico y simple con capacidad de recuperar muestras celulares que están ocupando las vías inferiores de equinos (Santos et al., 2007).

La posibilidad de ampliar los conocimientos teóricos y prácticos en el manejo de estas tecnologías y el mejoramiento del diagnóstico de patologías respiratorias, ha llevado a que en este artículo se plateé como objetivo evaluar el sistema respiratorio de algunos equinos de tracción en la ciudad de Porto Alegre (Brasil), a través del examen físico y endoscópico de sus vías aéreas, además del análisis citológico del lavado transtraqueal; el cual se realizó en la clínica de grandes animales del hospital veterinario de la Universidad Federal do Rio Grande do Sul. Este proyecto decidió hacerse dentro de la línea de investigación de los factores que afectan al caballo atleta con especialidad en el sistema respiratorio, y su premisa fue la búsqueda de algunas alteraciones del carácter respiratorio en animales destinados a la tracción de carrosa, realizando el diagnóstico y tratamiento oportunos a equinos, los cuales pertenecen a propietarios de bajos recursos económicos, y los destinados a competiciones, estableciendo el uso de estas técnicas de forma rutinaria, teniendo en cuenta que los líquidos traqueales de caballos sanos, contienen principalmente porcentajes adecuados de células epiteliales cilíndricas ciliadas, macrófagos, pequeños linfocitos y neutrófilos (Arias et al., 2013). En general, poco moco está presente, y las células predominantes son macrófagos alveolares y células epiteliales, algunos problemas que causan variación están relacionados probablemente con la técnica de colecta, y la dificultad para seleccionar caballos sanos con el fin de establecer parámetros normales (Tabla 1) (Santos et al., 2007).

El tipo celular varía con la enfermedad presente, las siguientes categorías son ampliamente conocidas, porque se aumenta:

- La proporción de neutrófilos, asociado a inflamación, obstrucción recurrente de vías aéreas (RAO), neumonía, pleuroneumonía, entre otras. 
- El número de hemosiderófagos, asociado a la hemorragia pulmonar inducida por el ejercicio.

- La cantidad de eosinófilos, asociado a enfermedad alérgica.

Los resultados bacteriológicos, pueden variar con el medio ambiente en el que se encuentre el animal, siendo mayor la probabilidad de aislar bacterias y hongos en animales estabulados (Hodgson y Hodgson, 2007).

Tabla 1. Valores de referencia para el contenido celular del líquido traqueo bronquial obtenido de equinos por aspiración con lavado transtraqueal percutáneo (LTP).

\begin{tabular}{lccc}
\hline Numero de caballos $\mathbf{( n )}$ & $\mathbf{1 5}$ & $\mathbf{9 2}^{\mathbf{2}}$ & $\mathbf{6 6}^{\mathbf{3}}$ \\
\hline Total células** & $4.9 \pm 2.7$ & - & - \\
Células escamosas $^{*}$ & 0 & $2.3 \pm 2.6$ & - \\
Células epiteliales* $^{*}$ & $19.8 \pm 6.1$ & 13.0 & $30.4 \pm 24.4$ \\
Macrófagos $^{*}$ & $65.0 \pm 13.7$ & $34.0 \pm 18.0$ & $44.1 \pm 23.2$ \\
Linfocitos $^{*}$ & $7.4 \pm 3.8$ & $4.9 \pm 3.1$ & $5.4 \pm 4.1$ \\
Neutrófilos $^{*}$ & $6.4 \pm 5.5$ & $39.0 \pm 21.0$ & $17.8 \pm 21.8$ \\
Eosinofilos* $^{*}$ & $1.2 \pm 1.4$ & $3.5 \pm 2.0$ & $0.7 \pm 2.2$ \\
Mastocitos $^{*}$ & $0.2 \pm 0.4$ & $1.6 \pm 1.9$ & - \\
Células plasmáticas $^{*}$ & - & $2.2 \pm 3.4$ & - \\
\hline
\end{tabular}

Fuente: ${ }^{1}$ Mair et al, (1987); ${ }^{2}$ Larson y Busch (1985); ${ }^{3}$ Sweeney et al, (1992).

${ }^{* *}$ Conteos celulares totales $(x 105 / \mathrm{ml}) ; y$ *diferencial $(\%)$

\section{METODOLOGÍA}

\section{Animales experimentales}

Fueron usados diez equinos adultos con edades entre los 7 y 15 años (Figura 1) destinados a la tracción de carrosa en la ciudad de Porto Alegre, de los cuales nueve eran provenientes del sector de clínica de grandes animales de la UFRGS, y uno utilizado en carreras hípicas, los cuales no poseían historial de vermifugación, vacunación o algún manejo medico sanitario. Los animales fueron alojados en corrales individuales, de $3.5 \times 3.5 \mathrm{~m}$ de área, para la cama se utilizó aserrín, el cual fue cambiado diariamente. La alimentación suministrada fue a base 
de concentrado comercial y heno de alfalfa 3 y $4 \mathrm{~kg}$ respectivamente, en 3 suministros durante el día, con agua ad libitum.

\section{Examen clínico}

Los animales fueron identificados, realizándose la toma de datos rutinarios que incluyen edad, peso, estado general, actitud y comportamiento, aspecto de las mucosas, temperatura corporal y frecuencias cardiaca y respiratoria. Posteriormente se realizó un examen clínico que incluyó inspección, percusión y auscultación del sistema respiratorio (Figura 2), en el cual se prestó especial atención a la presencia de algún tipo de secreción en la cavidad nasal, excesiva dilatación de las narinas, presencia de tos, disnea, ruidos respiratorios normales aumentados o anormales tales como crepitaciones, sibilancias o ronquidos.

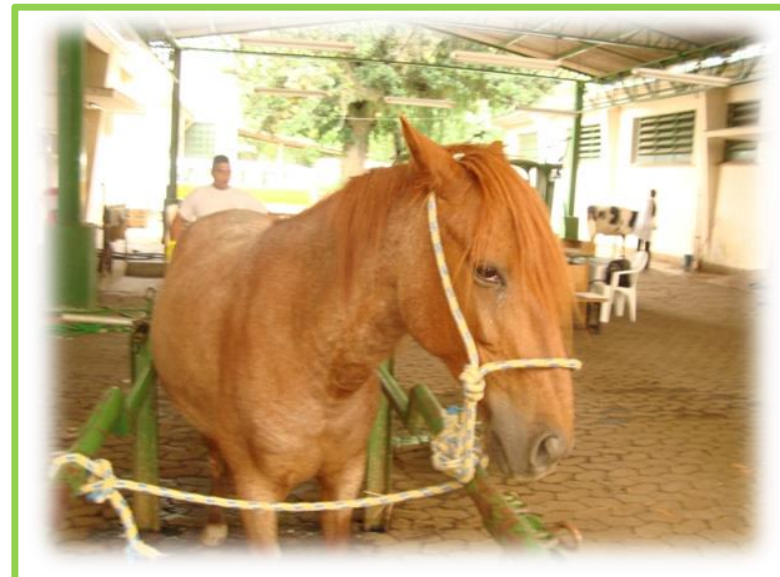

Figura 1. Equino utilizado en el experimento

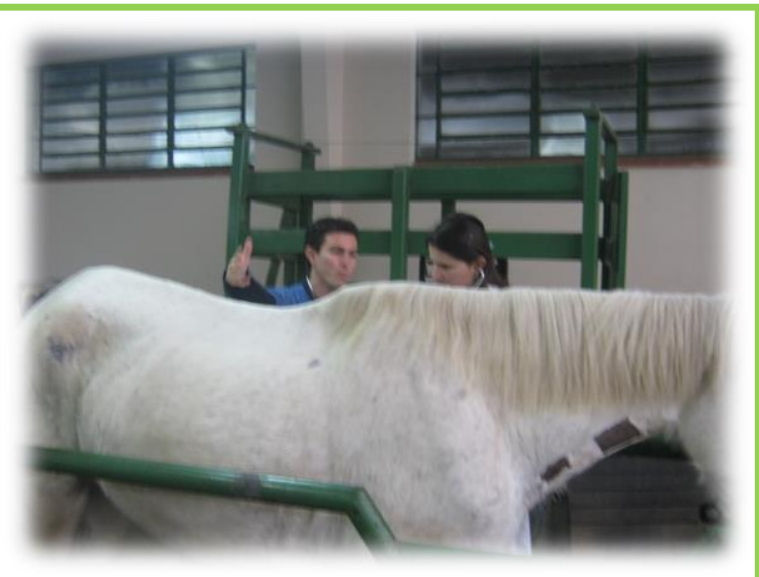

Figura 2. Examen clínico.

\section{Examen endoscópico de las vías aéreas}

La endoscopia es una técnica regularmente usada para evaluar las condiciones de las vías aéreas, la trasmisión de imagen básicamente se basa en la reflexión vía prisma en los sistemas de fibra óptica flexibles y video endoscopios (Arias et al., 2013).

Para realizar el procedimiento se estableció una óptima seguridad del paciente, personal y del equipo, para esto los caballos fueron colocados en bretes. La mayoría fueron examinados solamente con el uso de cachimbo, en los casos de 
animales con temperamento difícil, se puede utilizar Xilacina $(0.9 \mathrm{mg} / \mathrm{kg} \mathrm{IV}) \circ$ detomidina (0.1 mg/kg IV) y butorfanol (0.1 mg/kg IV), (Wilfong y Waldridg, 2009), teniendo en cuenta que los agonistas $\alpha_{2}$ adrenergicos pueden alterar la funcionalidad de la laringe.

El examen endoscópico se llevó acabo en 4 animales, este fue realizado con un colonoscopio (PENTAX EPM 320 ${ }^{\circledR}$ ), con $1.7 \mathrm{~m}$ de longitud y $12 \mathrm{~mm}$ de diámetro externo. Cuando se evaluaron las cámaras nasales, el endoscopio se introdujo rápido y suavemente en el meato ventral mientras la narina se mantuvo abierta (Figura 3). Después de la inserción pudo examinarse durante la introducción, el meato ventral, la concha ventral y el aspecto ventral del septo nasal, las estructuras más dorsales pudieron ser observadas cuando se retiró el endoscopio, estas incluyen la concha dorsal, el septo nasal y los meatos dorsal, medial y común. El objetivo de examinar las fosas nasales es detectar lesiones como infecciones, neoplasias, cuerpos extraños, traumatismos y/o secreciones (Semeco et al., 2011).

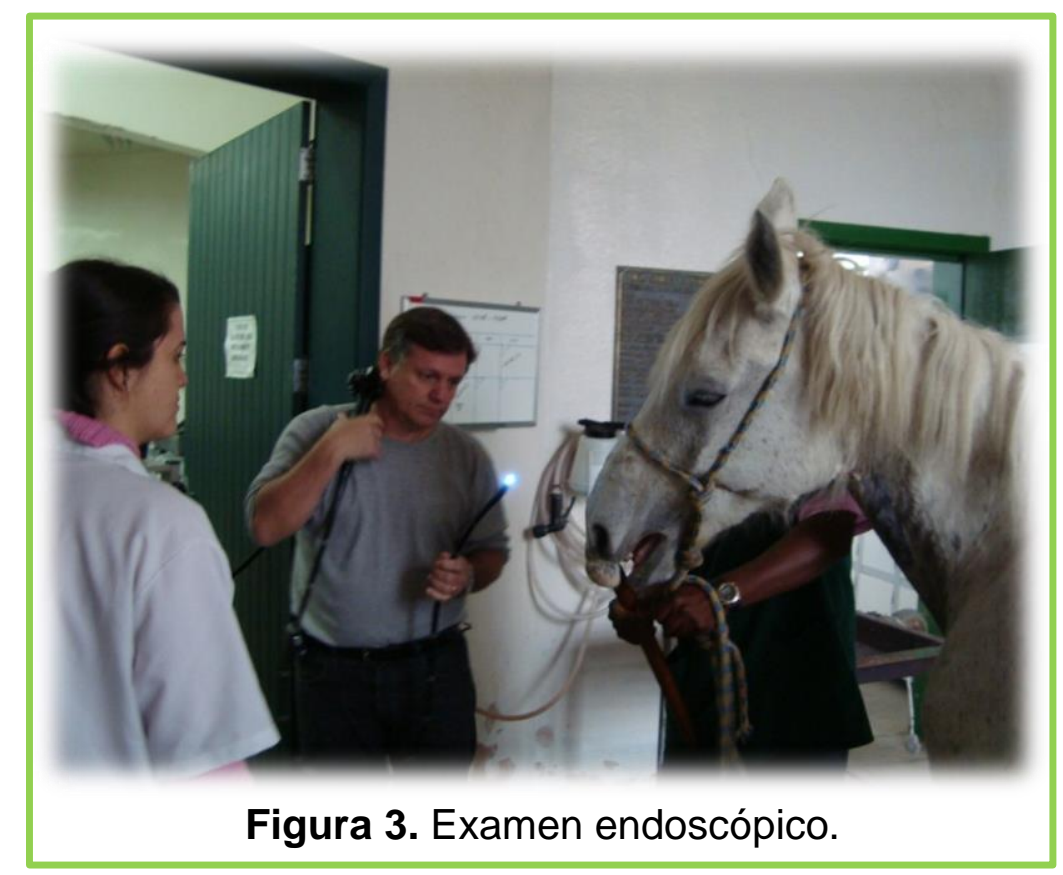

La faringe está dividida por el paladar blando en partes dorsal y ventral, en la parte anterior estas son conocidas respectivamente, como nasofaringe y orofaringe, y en la parte caudal se encuentra la laringofaringe dorsal y ventral. Inicialmente el 
endoscopio se introdujo en la nasofaringe, donde es visible el paladar blando en la parte ventral, luego se avanza hacia el rostro y dorso lateral, para el receso dorsal de la faringe y aberturas para los tubos auditivos, respectivamente. La laringe generalmente es visible al fondo y fue examinada moviendo el endoscopio profundamente en la faringe. El observador debe estar familiarizado con la estructura del paladar blando y con la manera por la cual la laringe rostral (epiglotis y procesos corniculados del cartílago aritenoides) se inserta a través de la abertura intra-faríngea en el paladar blando. Los objetivos de analizar esta región del sistema respiratorio consisten en evaluar las lesiones visibles y la competencia funcional de estructuras como el paladar blando y la laringe (Arias et al., 2013). En esta porción se prestó atención a la presencia o no de dislocamiento dorsal del paladar blando.

La laringe fue examinada avanzando el endoscopio al interior de la nasofaringe, la cual debe tener una disposición y anatomía normal al igual que sus cartílagos constituyentes, detectando anormalidades estáticas y funcionales. Los cartílagos aritenoides (CA) en abducción son particularmente importantes, debido al alto grado de hemiplejia laríngea y de la condición conocida como paresia o laringe asincrónica, su evaluación es realizada con el animal en reposo siendo subjetiva, y puede variar con la sedación, aplicación de cachimbo o por la visualización de cada una de las narinas (Semeco et al., 2011). En esta porción se evaluó la forma y tamaño de los CA, y el grado de neurolaringopatia, según el sistema propuesto por Hackett, (1992): Grado 1: Abducción completa durante el ejercicio y aducciones sincrónicas completas de los CA derecho e izquierdo (Tabla 6). Grado 2: Movimientos asincrónicos, vibración, debilidad abductora del CA izquierdo durante cualquier fase de la respiración, además se observa que la abducción completa del mismo puede ser provocada por: oclusión nasal o deglución, y ejercicio. Grado 3: Movimientos asincrónicos, vibración, debilidad abductora del CA izquierdo durante cualquier fase de la respiración. La abducción completa no puede ser inducida y solo ocurre durante el ejercicio en la mayoría de los caballos, aunque algunos entran en colapso dinámico del CA. Grado 4: Acentuada asimetría de la laringe en reposo sin movimiento significativo durante cualquier 
fase de la respiración, todos los caballos entran en colapso dinámico del aritenoide.

La tráquea y los bronquios principales fueron examinados cuando el caballo estuvo en el brete, la mayoría permitieron el paso del endoscopio flexible por la porción proximal de la tráquea sin evidencias de estrés. El examen de los bronquios se realizó con un endoscopio de una longitud mínima de $150 \mathrm{~cm}$; a medida que éste avanzaba hacia las porciones más distales de la tráquea, como la bifurcación en bronquios principales derecho e izquierdo, el reflejo de tos fue inducido, el cual se minimiza destilando algunos mililitros de anestésico local por el canal de biopsia del endoscopio a medida que éste avanza por la vía aérea, siendo sistemático el examen de cada bronquio principal. Para Pollock et al., (2009) el procedimiento es rápido, con mínimo estrés para el animal, y aporta información valiosa por la visualización directa de las vías respiratorias en el momento del paso del endoscopio donde se evaluó: coloración de la mucosa traqueal, presencia de secreciones, reactividad traqueal, y presencia de hemorragia.

La presencia de sangre puede ser observada en la mayoría de los caballos después de ser sometidos a ejercicio fuerte o por largo periodo de tiempo (hasta 7 días) (Moran et al., 2003), la cantidad de sangre en las vías puede variar de acuerdo al grado de la hemorragia, éste examen sirve para determinar la "hemorragia inducida por el ejercicio"; la clasificación de la misma según el volumen de sangre observado y su distribución a lo largo de las vías aéreas (Pereira et al., 2014; Baccarin, 2005), se puede resumir en los siguientes grados: Grado 1: presencia de pequeñas estrías o coágulos presentes en el tercio distal de la tráquea; Grado 2: distribución de hilos de sangre aleatoria (no uniforme), por toda la extensión de la tráquea, lo mismo que coágulos mayores; Grado 3: sangre distribuida uniformemente en toda la extensión de la tráquea; Grado 4: cantidad abundante de sangre por toda la tráquea, laringe, faringe y fosas nasales; Grado 5: exacerbación del cuadro anterior y epistaxis. 


\section{Colecta y evaluación de las secreciones de las vías aéreas inferiores: lavado y aspirado trans-traqueal percutáneo}

La enfermedad de las vías aéreas inferiores es diagnosticada por citología y microbiología de las secreciones respiratorias, para lo cual se colectan muestra de secreción de la tráquea o de las vías aéreas inferiores (Flórez, 2013). El examen citológico de las vías aéreas, fue realizado a través del lavado transtraqueal, aspirado traqueal, lavado traqueo bronquial y lavado bronco alveolar (Biavia et al., 2006), el cual se refiere a la colección de líquido del árbol traqueo bronquial, usando una técnica percutánea para inyectar liquido de lavado y después colectarlo por aspiración. La aspiración transtraqueal se refiere al mismo proceso pero sin inyectar liquido de lavado (Dos Santos y Da Graça, 1999). Esta prueba fue adaptada a los equinos por Mansmann y Knigth, (1972) quienes constataron la gran utilidad de este método para la identificación de agentes patógenos en las afecciones respiratorias de carácter infeccioso, además su implementación tiene bajo costo.

La técnica transtraqueal posee la ventaja de eliminar el paso por la cavidad nasal y porciones del tracto respiratorio superior, eliminando el riesgo de contaminación de la muestra por microorganismos de la flora local de la nasofaringe (Hewson y Viel, 2002). Algunas desventajas del lavado traqueo bronquial percutáneo son resultantes de la aspiración percutánea, que incluyen enfisema subcutáneo, infección, condritis, perdida del catéter en las vías aéreas y hemorragia local (Engels et al., 2009). Este procedimiento fue realizado en un área aproximada de $5 \times 5 \mathrm{~cm}$, centrada sobre el tercio medio de la tráquea, se inyectaron subcutáneamente $5 \mathrm{ml}$ de solución anestésico local, entre un par de anillos traqueales adyacentes, se realizó una pequeña incisión en la piel, y una aguja calibre 16 fue insertada en los anillos traqueales y direccionada hacia abajo (Figura 4), teniendo cuidado para no causar un traumatismo en la pared opuesta de la tráquea, el bisel de la aguja estuvo posicionado hacia abajo, para minimizar el peligro de cortar accidentalmente el catéter, que avanzó hasta la entrada de la cavidad torácica (Castillo et al., 2013). 
Para realizar el lavado trans-traqueal percutáneo (LTP), la solución salina estéril fue rápidamente inyectada e inmediatamente aspirada, repitiendo el procedimiento hasta lograr un volumen adecuado (Figura 5). En el LTP es común recuperar una cantidad menor a la inyectada, y las repeticiones del procedimiento pueden inducir la tos, lo que puede generar dislocaciones del tubo hacia la faringe, por eso se recomienda el uso de un tubo grueso. En la aspiración transtraqueal percutánea (ATP), las secreciones fueron simplemente aspiradas, sin inyectarse previamente líquido de lavado, realizando el procedimiento solo cuando se tuvo un volumen copioso de secreción. Finalmente el tubo fue removido y la incisión suturada, y se puesto un vendaje compresivo, aunque en la mayoría de los casos no precisa ninguno de las dos acciones, estas muestras fueron sometidas a evaluación citológica y bacteriológica (Flórez, 2013).

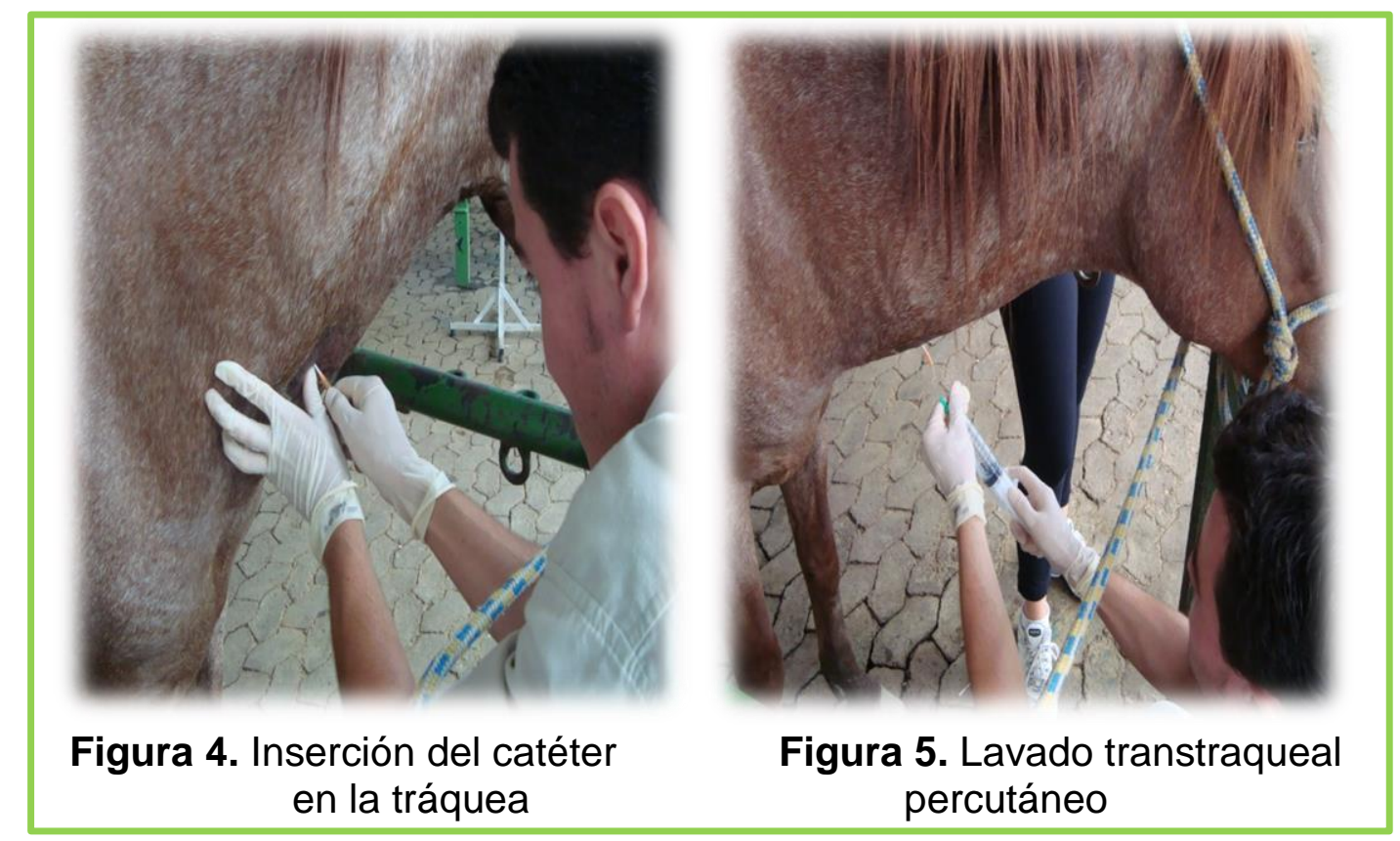

\section{Evaluación citológica}

La evaluación citológica de los aspirados traqueales, es hecha por: el conteo total de células en la cámara de Neubauer, y por la evaluación diferencial de los tipos celulares, para esta última, diferentes técnicas de coloración, como, Diff-Quick, Wright-Giemsa, Leishman's, Azul da Prússia, My-Grunwald, Azul de Toluidina y Romanovski (Hewson y Viel, 2002; Hodgson y Hodgson, 2003). 
Para el procedimiento se realizó la identificación y se determinó el volumen colectado en dos tubos, de la muestra contenida en el tubo sin EDTA, se realizó un examen físico, el cual consistió en determinar el color, aspecto y consistencia, y posteriormente, se guardó como segunda opción para realizar la citología. De la muestra contenida en el tubo con EDTA, se tomó $1 \mathrm{ml}$ para llevar acabo el conteo de células nucleadas y eritrocitos en la cámara de Neubauer con un aumento de 40x, esta muestra no fue sometida a ningún tipo de dilución. Luego de realizar el conteo, se calculó el número de células presentes en las muestras usando las siguientes formulas:

\section{CALCULO DE CÉLULAS NUCLEADAS}

$\frac{\text { \# Células contadas } \times 10}{\# \text { Cuadros contados }(9)}$

\section{CALCULO DE ERITROCITOS}

\# Células contadas en 5 cuadrantes

$\overline{\text { Área contada }\left(\frac{1}{5}\right) \times \text { cámara }\left(\frac{1}{10}\right) \times \text { dilución }(1)}$
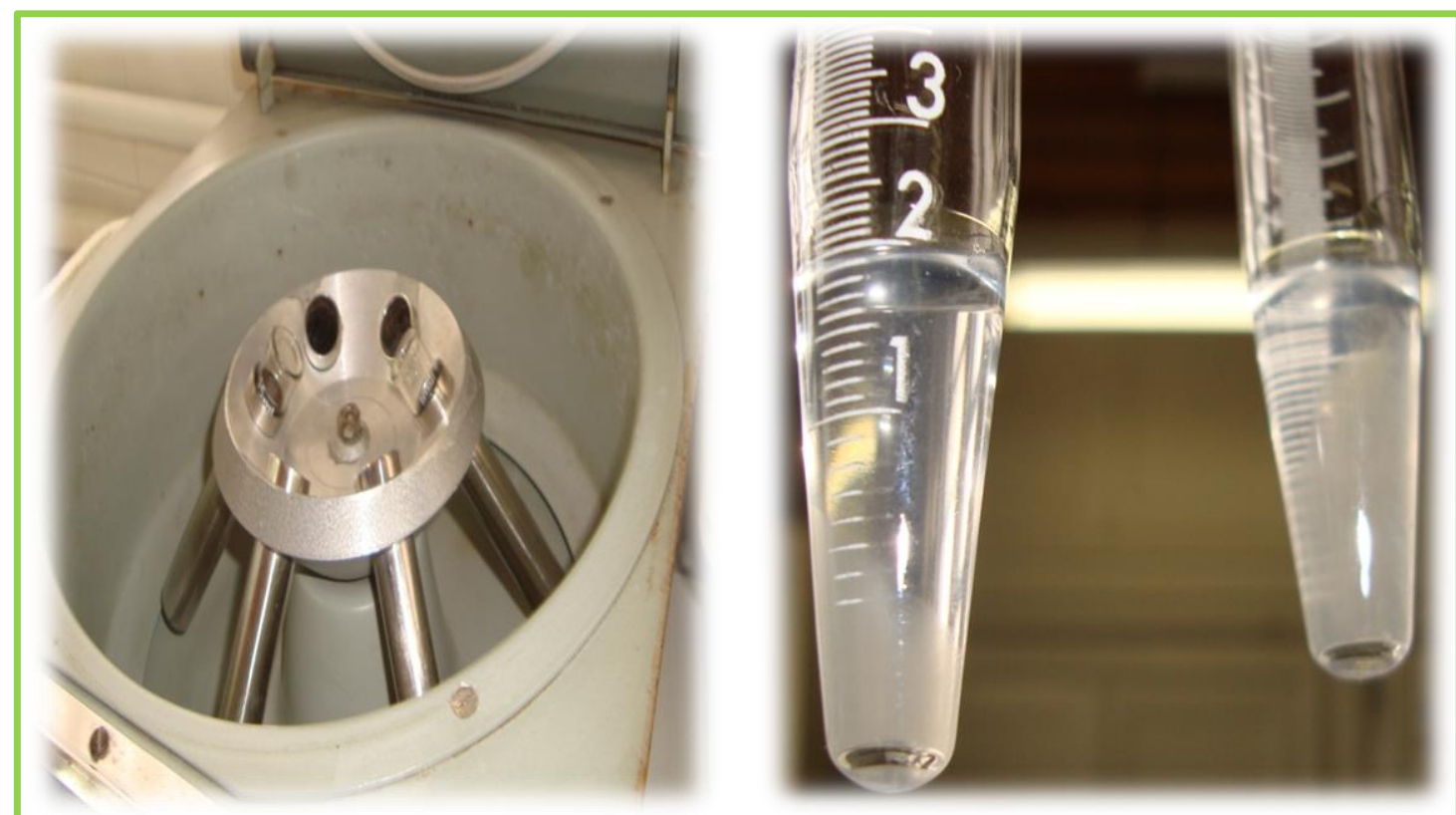

Figura 6. Centrifugación de los lavados traqueales

De la muestra contenida en el tubo con EDTA se tomó $1 \mathrm{ml}$, la cual se sometió a centrifugación durante 10 minutos a 1500 rpm (Figura 6), del precipitado obtenido se realizaron 3 láminas tipo squash, que se tiñeron con el método Panóptico rápido, luego se llevó a cabo el conteo diferencial de células con un aumento de 
100x, además se observaron las características morfológicas y las principales alteraciones celulares.

Para realizar otro conteo diferencial se tomó $1 \mathrm{ml}$ de la muestra que no fue centrifugada y se llevó a la cámara de suta, en la cual quedo en reposo durante 1 hora, para que el exceso de líquido fuera absorbido, y de esta manera las células se concentren para mejorar la observación de las mismas, posteriormente se realizó coloración por el método Panóptico

\section{Hemograma y determinación de fibrinógeno plasmático}

Las muestras de sangre fueron obtenidas por medio de venipunción yugular, tomando un volumen de $3 \mathrm{ml}$, depositándolos en tubos con EDTA, y posteriormente enviadas al laboratorio clínico veterinario (LACVET) del hospital de clínicas veterinarias de la Universidad Federal do Rio Grande do Sul (UFRGS).

\section{Análisis estadístico}

Se realizó un análisis estadístico descriptivo utilizando el programa SPSS versión 19, haciendo las estimaciones de: error típico, mediana, moda, desviación estándar, varianza de la muestra, rango, máximo, mínimo y nivel de confianza. Se analizaron las siguientes variables: edad de los equinos relacionándola con la frecuencia cardiaca, respiratoria, temperatura, eritrograma, leucograma, fibrinógeno plasmático, citología de lavado traqueal y resultados de endoscopias.

\section{RESULTADOS Y DISCUSIÓN}

La edad de los animales experimentales (Gráfica 1) fue similar al del estudio de Zuluaga, (2011) quien realizó endoscopias en equinos de salto, intolerantes al ejercicio, en una población de 6 a 12 años, encontrando que, de ocho animales estudiados, cinco presentaron hemiplejía laríngea idiopática izquierda, lo que representa el $62 \%$ de la población examinada. Así mismo se encontraron dos equinos con afecciones alérgicas respiratorias, lo que sugiere que el manejo ambiental es un factor importante para su cuidado. Por último se encontró un animal que se desempeña en una baja intensidad, con hemorragia pulmonar 
inducida por el ejercicio, una patología descrita en caballos que se desempeñan en actividades de máximo esfuerzo e intensidad.

La estadística descriptiva de los parámetros fisiológicos (Tabla 2) como: frecuencia cardiaca $(39.2 \pm 1.44 \mathrm{lpm})$, frecuencia respiratoria $(19.7 \pm 2.37 \mathrm{rpm}) \mathrm{y}$ temperatura $\left(38.25 \pm 0.08^{\circ} \mathrm{C}\right)$, valores que difieren a los reportado por Perrone et al., (2006) (31.27 $\pm 1.18 \mathrm{lpm}, 16.18 \pm 1.44 \mathrm{rpm}$ y $37.14 \pm 0.09^{\circ} \mathrm{C}$ respectivamente).

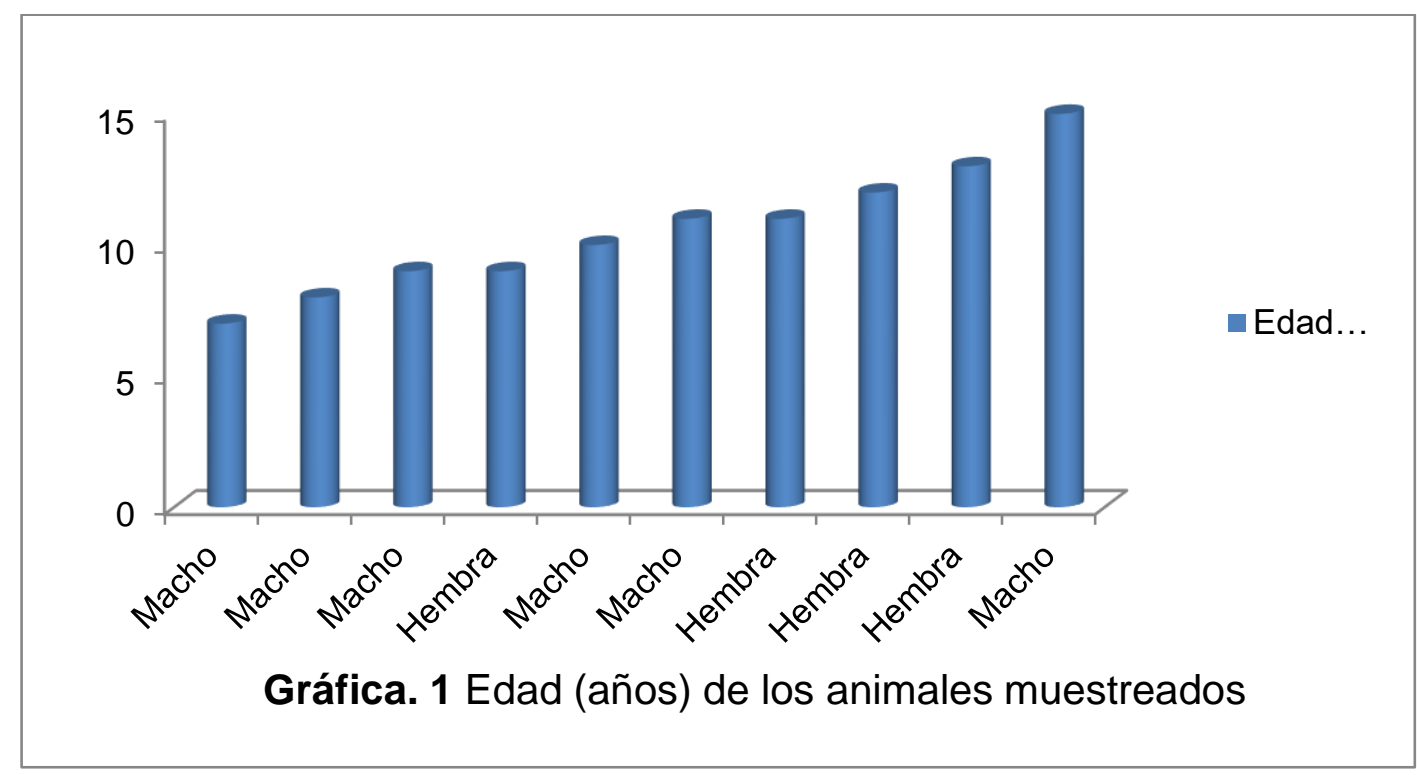

Tabla 2. Parámetros fisiológicos de los equinos examinados

\begin{tabular}{lccc}
\hline Parámetros estadísticos & $\begin{array}{c}\text { Frecuencia } \\
\text { cardiaca (Ipm) }\end{array}$ & $\begin{array}{c}\text { Frecuencia } \\
\text { respiratoria (rpm) }\end{array}$ & $\begin{array}{c}\text { Temperatura } \\
\left({ }^{\circ} \mathbf{C}\right)\end{array}$ \\
\hline Media & 39.2 & 19.7 & 38.25 \\
Error típico & 1.44 & 2.37 & 0.08 \\
Mediana & 40 & 16 & 38.25 \\
Moda & 40 & 16 & 38.3 \\
Desviación estándar & 4.54 & 7.48 & 0.26 \\
Varianza de la muestra & 20.62 & 56.01 & 0.07 \\
Rango & 12 & 25 & 0.8 \\
Mínimo & 32 & 12 & 37.9 \\
Máximo & 44 & 37 & 38.7 \\
Nivel de confianza (95.0\%) & 3.25 & 5.35 & 0.19 \\
\hline
\end{tabular}


El análisis estadístico del eritrograma (Tabla 3 ) donde el hematocrito $34.7 \pm 1.09 \%$ fue similar al encontrado por Perrone et al., (2006) (33.55 $\pm 1.52 \%$ ), y así mismo el recuento de eritrocitos $(7.25 \pm 0.2710 \% / \mathrm{ml})$ está dentro del mismo rango, según estudios realizados en caballos criollos colombianos (6.0-9.8. $\left.\times 10^{6} / \mathrm{ml}\right)$, observándose igual comportamiento con las siguientes variables: hemoglobina (11.34 $\pm 0.042 \mathrm{~g} / \mathrm{dl})$, volumen corpuscular medio (49.85 $\pm 0.96 \mathrm{fl})$, concentración de hemoglobina corpuscular media $(32.77 \pm 0.45 \mathrm{~g} / \mathrm{dl})$ y plaquetas $(183.8 \pm 10.98$ x 103/ml), (10.7-15.8 g/dl, 43-56 fl, 29-37 g/dl y 112-394 x 103/ml respectivamente) (Castillo et al., 2011); mientras que las proteínas plasmáticas totales encontradas $(7.3 \pm 0.13 \mathrm{~g} / \mathrm{dl})$ difieren con lo reportado por Perrone et al., (2006) $(6.54 \pm 0.16$ $\mathrm{g} / \mathrm{dl})$.

Tabla 3. Eritrograma y fibrinógeno plasmático

\begin{tabular}{|c|c|c|c|c|c|c|c|c|}
\hline $\begin{array}{l}\text { Parámetros } \\
\text { Estadístico }\end{array}$ & $\begin{array}{l}\text { Eritrocitos } \\
\left(\times 10^{6} / \mathrm{ml}^{1}\right.\end{array}$ & $\underset{(g / d l)^{2}}{H b}$ & $\begin{array}{l}\text { Hto } \\
(\%)^{3}\end{array}$ & $\begin{array}{c}\operatorname{VCM} \\
(\mathrm{fl})^{4}\end{array}$ & $\begin{array}{l}\text { CHCM } \\
(\mathrm{g} / \mathrm{dl})^{5}\end{array}$ & $\begin{array}{c}\text { Plaquetas } \\
\left(\times 10^{3}\right. \\
/ \mathrm{ml})^{6} \\
\end{array}$ & $\begin{array}{l}\text { PPT } \\
\left(\mathrm{g} / \mathrm{l}^{7}\right.\end{array}$ & $\begin{array}{c}\text { Fibrin } \\
(g / l)^{8}\end{array}$ \\
\hline Media & 7.25 & 11.34 & 34.7 & 49.85 & 32.77 & 183.8 & 73.1 & 2.1 \\
\hline Error típico & 0.27 & 0.42 & 1.09 & 0.96 & 0.45 & 10.98 & 1.30 & 0.18 \\
\hline Mediana & 7.37 & 11.15 & 34.5 & 49.61 & 32.91 & 199.5 & 72.5 & 2 \\
\hline Moda & - & - & 35 & - & 32.5 & 200 & 72 & 2 \\
\hline $\begin{array}{l}\text { Desviación } \\
\text { estándar }\end{array}$ & 0.87 & 1.32 & 3.47 & 3.04 & 1.42 & 34.77 & 4.12 & 0.57 \\
\hline $\begin{array}{l}\text { Varianza de } \\
\text { la muestra }\end{array}$ & 0.75 & 1.75 & 12.01 & 9.22 & 2.02 & 1205.96 & 16.99 & 0.32 \\
\hline Rango & 2.72 & 5 & 13 & 10.74 & 4.29 & 104 & 14 & 2 \\
\hline Mínimo & 5.99 & 9.1 & 30 & 44.35 & 30.26 & 126 & 66 & 1 \\
\hline Máximo & 8.71 & 14.1 & 43 & 55.09 & 34.55 & 230 & 80 & 3 \\
\hline $\begin{array}{l}\text { Nivel de } \\
\text { confianza } \\
(95.0 \%)\end{array}$ & 0.62 & 0.95 & 2.48 & 2.17 & 1.02 & 24.84 & 2.95 & 0.41 \\
\hline
\end{tabular}

Hb: hemoglobina; Hto: hematocrito, VCM: volumen corpuscular medio, CHCM: concentración de hemoglobina corpuscular medio, PPT: proteínas plasmáticas totales, Fibrin: fibrinógeno.

Rango de referencia: ${ }^{1}(7.5-10.0),{ }^{2}(10.0-14.0),{ }^{3}(29-43),{ }^{4}(37-58.5),{ }^{5}(31-37),{ }^{6}(100-350),{ }^{7}(56-88)$, $8(1-3)$.

El leucograma (Tabla 4), donde los leucocitos totales $(9880 \pm 470 / \mathrm{ml})$, neutrófilos $(5910 \pm 560 / \mathrm{ml})$, eosinófilos $(359.2 \pm 70.8 / \mathrm{ml})$ y linfocitos $(3420 \pm 420 / \mathrm{ml})$ se encuentran dentro de los rangos obtenidos por Castillo et al., (2011) (5235-12124, 
2877-6946, 0.576 y $1021-5896 / \mathrm{ml}$ respectivamente), mientras que los monocitos $(339.8 \pm 50.12 / \mathrm{ml})$ se reportan altos en comparación al estudio de este último autor $(0-145 / \mathrm{ml})$.

Tabla 4. Leucograma

\begin{tabular}{|c|c|c|c|c|c|c|}
\hline $\begin{array}{l}\text { Parámetros } \\
\text { Estadístico }\end{array}$ & $\begin{array}{c}\text { Leucocitos } \\
\text { totales } \\
\left(\# \times 10^{6} / \mathrm{ml}\right)\end{array}$ & $\begin{array}{l}\text { Neutrófilos }^{2} \\
\left(\# \times 10^{6} / \mathrm{ml}\right)\end{array}$ & $\begin{array}{l}\text { Eosinófilos }^{3} \\
\quad(\# \times \mathrm{ml})\end{array}$ & $\begin{array}{c}\text { Basófilos }^{4} \\
\text { (\# x ml) }\end{array}$ & $\begin{array}{l}\text { Monocitos }^{5} \\
(\# \times \mathrm{ml})\end{array}$ & $\begin{array}{l}\text { Linfocitos }^{6} \\
\quad \# \times 10^{6} \\
/ \mathrm{ml})\end{array}$ \\
\hline Media & 9.88 & 5.91 & 359.2 & 21.5 & 339.8 & 3.42 \\
\hline Error típico & 0.47 & 0.56 & 70.80 & 14.37 & 50.12 & 0.42 \\
\hline Mediana & 10.1 & 6.28 & 352 & 0 & 301.5 & 2.9 \\
\hline Moda & 10.1 & 6.5 & 404 & 0 & - & - \\
\hline $\begin{array}{l}\text { Desviación } \\
\text { estándar }\end{array}$ & 1.47 & 1.60 & 223.89 & 45.43 & 158.51 & 1.32 \\
\hline $\begin{array}{l}\text { Varianza de } \\
\text { la muestra }\end{array}$ & 2.17 & 2.56 & 50127.07 & 2063.83 & 25124.4 & 1.75 \\
\hline Rango & 4.3 & 5.1 & 798 & 114 & 486 & 3.46 \\
\hline Mínimo & 7.4 & 3.4 & 0 & 0 & 120 & 2.22 \\
\hline Máximo & 11.7 & 8.5 & 798 & 114 & 606 & 5.68 \\
\hline $\begin{array}{l}\text { Nivel de } \\
\text { confianza } \\
(95.0 \%)\end{array}$ & 1.05 & 1.14 & 160.16 & 32.50 & 113.39 & 0.95 \\
\hline
\end{tabular}

Rango de referencia: ${ }^{1}(5.8-13.2),{ }^{2}(2.9-7.0),{ }^{3}(0-600),{ }^{4}(0-60),{ }^{5}(0-500),{ }^{6}(2-7.5)$.

Los resultados de la citología del lavado traqueal (Tabla 5), en lo relacionado al porcentaje de células epiteliales $(42.3 \pm 9.35)$, y linfocitos $(3.3 \pm 1.13)$ presentaron valores similares a los analizados por Flórez, (2013) en un estudio realizado en Argentina con caballos sometidos a diferente actividad física (40.32-42.32\% y $2.26-4.53 \%$ respectivamente). No sucedió igual con macrófagos (20.1 \pm 5.35 ), neutrófilos $(26.4 \pm 8.37)$ y eosinófilos $(2.7 \pm 1.78)$, puesto que los valores fueron superiores a los de este mismo autor $(45.68-47.16 \%, 7.74-8.47 \%$ y $0.21-0.26 \%$ respectivamente). Las diferencias podrían ser atribuidas a la fuerte correlación (Flórez, 2013) entre las variables estudiadas, cuando es positiva si hay presencia de un tipo celular, también hay de otro, y por el contrario es negativa cuando al aumentar una línea celular disminuye otra. 
Flórez, (2013) en su estudio encontró que los macrófagos alveolares fueron la célula predominante en las muestras obtenidas de lavados traqueales en caballos de salto sometidos a diferentes exigencias deportivas, resultado coincidente con otros reportes bibliográficos (Hoffman et al., 2002; Hodgson y Hodgson, 2007). Al igual que en este trabajo, el autor observó en algunos casos la presencia de material fagocitado en su interior, lo cual evidencia una actividad normal por parte de estas células. Ahora bien, se considera que el porcentaje de neutrófilos en las vías respiratorias de los caballos sanos debe ser menor de un $20 \%$ en el lavado traqueobronquial (Hodgson y Hodgson, 2007); Hoffman et al., (2008), lo confirmó a través de su estudio, puesto que los animales evaluados tuvieron valores más altos y presentaban algún tipo de problema respiratorio (Tabla 5).

Tabla 5. Citología de lavado traqueal

\begin{tabular}{|c|c|c|c|c|c|c|}
\hline Estadístico & CEES (\%) & CE (\%) & M (\%) & $\mathbf{N}(\%)$ & $E(\%)$ & L (\%) \\
\hline Media & 5,2 & 42,3 & 20,1 & 26,4 & 2,7 & 3,3 \\
\hline Error típico & 2,05 & 9,35 & 5,35 & 8,37 & 1,78 & 1,13 \\
\hline Mediana & 3 & 44 & 16,5 & 13 & 0 & 2 \\
\hline Moda & 0 & - & 4 & - & 0 & 2 \\
\hline $\begin{array}{l}\text { Desviación } \\
\text { estándar }\end{array}$ & 6,49 & 29,55 & 16,93 & 26,47 & 5,62 & 3,56 \\
\hline $\begin{array}{l}\text { Varianza de la } \\
\text { muestra }\end{array}$ & 42,18 & 873,34 & 286,54 & 700,71 & 31,57 & 12,68 \\
\hline Rango & 18 & 85 & 56 & 82 & 18 & 12 \\
\hline Mínimo & 0 & 7 & 4 & 5 & 0 & 0 \\
\hline Máximo & 18 & 92 & 60 & 87 & 18 & 12 \\
\hline $\begin{array}{l}\text { Nivel de confianza } \\
(95,0 \%)\end{array}$ & 4,65 & 21,14 & 12,11 & 18,94 & 4,02 & 2,55 \\
\hline
\end{tabular}

CEES = células epiteliales escamosas superficiales; $\mathrm{CE}=$ células epiteliales; $\mathrm{M}=$ macrófagos; $\mathrm{N}$ = neutrófilos; $E$ = eosinófilos; $L=$ linfocitos.

En otro estudio Sweeney et al., (1992) evaluaron 66 caballos de corrida estabulados, encontrando un $8 \%$ de bacterias aeróbicas de reconocida patogenicidad, $24 \%$ de tipo transitorias y $74 \%$ resultaron negativos. En los caballos de corrida $(\mathrm{N}=36)$, que se encontraban en el campo, sus muestras presentaron un $8 \%$ de bacterias de reconocida patogenicidad, $64 \%$ transitorias y 
un $28 \%$ dieron negativos. En cuanto al cultivo de anaerobios, todos fueron negativos, presentando crecimiento de hongos en ambos grupos, y la bacteria que se observó en mayor proporción fue Nocardia spp para ambos grupos.

Respecto a los resultados de la endoscopia (Tabla 6), en algunos animales fue observada la presencia de una cantidad normal de moco y ausencia de bacterias (sanos), mientras que en otros se constató un aumento de la producción de moco y cantidad significativa de bacterias en el medio extracelular y en la superficie de las células escamosas, o picnosis y degeneración celular, o fagocitos y restos celulares, y en una muestra se observó presencia de hongos (conídeos) en el fondo extracelular. Souza et al., (2014) en un análisis de secreción traqueal y examen endoscópico realizado en caballos cuarto de milla sanos, encontraron en un ejemplar hiperplasia folicular linfoide grado II, en otro condritis epiglótica y en uno neurolaringopatia grado III, que comparándolo con los equinos utilizados en este estudio ninguno presentó anormalidades de este tipo, ya que no fue observada la presencia de hemiplejia laríngea, puesto que en todos los casos la abducción de los CA fue normal, completa y sincrónica, lo cual bajo el esquema propuesto por Hackett, (1992) se clasificaría como neurolanrigopatia Grado I (Tabla 6).

Tabla 6. Resultados endoscopias

\begin{tabular}{ccccccccc}
\hline & \multicolumn{3}{c}{ Vías Aéreas Superiores } & \multicolumn{5}{c}{ Vías Aéreas Inferiores } \\
\hline $\begin{array}{c}\text { Fosas } \\
\text { nasales }\end{array}$ & HFL & DDPB & Epiglotis & $\begin{array}{c}\text { Neuro- } \\
\text { laringopatia } \\
\text { (grado) }\end{array}$ & Tráquea & $\begin{array}{c}\text { Secreción } \\
\text { Traqueal }\end{array}$ & Carina & $\begin{array}{c}\text { Hemorragia } \\
\text { pulmonar }\end{array}$ \\
\hline HE & - & S/D & - & I & - & - & - & - \\
- & $\cdot$ & S/D & - & I & - & - & - & - \\
- & $\cdot$ & DI & - & I & HE/HR & SS & HE & - \\
- & S/D & - & I & HR & SS & ED & - \\
\hline
\end{tabular}

HFL: hiperplasia folicular linfoide; DDPB: dislocamiento dorsal de paladar blando; (-): normal; HE: hiperemica; S/D: sin dislocamiento; DI: dislocamiento intermitente; HR: híper reactiva; ED: edematizada; SS: secreción seromucosa.

En casos de faringitis agudas se encontró la mucosa congestionada y presencia de exudado, que generalmente se acumula en el receso faríngeo. Asimismo, pudo 
apreciarse incremento en el tamaño de las formaciones linfáticas distribuidas por el techo dorsal de la faringe y de la tonsila faríngea. No obstante, la hiperplasia de los folículos linfáticos faríngeos se aprecia con más frecuencia en los casos de faringitis crónicas, en las cuales es el síntoma predominante (Arias et al., 2013).

\section{CONCLUSIONES}

Aunque cerca de la mitad de los animales presentaron en la endoscopia un proceso inflamatorio, no fue posible evidenciarlo en el examen clínico, puesto que los cambios celulares no fueron suficientes para generar sintomatología evidente: como la disminución del desempeño, sonidos respiratorios anormales (estertores, estridores, sibilancias y tos) o secreción nasal.

Esta experiencia confirma que el lavado traqueobronquial es un método de diagnóstico rápido, preciso y asequible, que revaloriza la aplicabilidad de la citología como ayuda diagnostica en patologías de vías respiratorias distales, y abre la puerta para realizar futuros estudios acerca del impacto del ejercicio en la dinámica celular inflamatoria a nivel del sistema respiratorio en el equino. Así mismo, la citología del lavado traqueal es una herramienta fundamental para el diagnóstico de las enfermedades respiratorias, ya que permite la identificación de trastornos funcionales, donde se visualiza el tipo celular predominante, lo que permite una identificación del proceso inflamatorio existente.

\section{REFERENCIAS BIBLIOGRÁFICAS}

1. Arias M, Zuluaga D, Berrio C, Giraldo R, Escobar M. Hallazgos endoscópicos de las vías respiratórias altas en equinos de la Policia Metropolitana de Medellín, Colombia. Rev. Med. Vet. Zoot, 60 (1): 23-31. 2013.

2. Baccarin R. Diagnóstico e tratamento das pneumopatias de esforço. En: $2^{\circ}$ Simpósio Internacional do Cavalo Atleta e 4a Semana do Cavalo-SIMCAV. Belo Horizonte, Minas Gerais: Universidade Federal de Minas Gerais, p 12-28. 2005.

3. Biava J. Avaliação clínica, endoscópica e citológica da hemorragia pulmonar induzida pelo exercício (eiph) em cavalos da raça quarto de milha, Tesis MSc Medicina Veterinaria, Universidade Estadual Paulista, Facultade de Medicina Veterinária e Zootecnia, Botcatu, São Pablo, 107 p. 2007.

4. Biava J, Gonçalves R, Dornbusch P, Michelotto J, Biondo A, Cassou F, Zanotto G, Telles J. Avaliação cínica e citológica do trato respiratório de 
cavalos da raça Quarto de Milha após exercício. Archives of Veterinary Science, 11 (1): 60-65. 2006.

5. Castillo C, Tobón M, Cano C, Mira J, Suárez A, Vásquez E. Valores hematológicos en caballos criollos colombianos del Valle de Aburrá. En: Serie Lasallista de investigación y ciencia. Ed Corporación Universitaria Lasallista, Cap. 15: 245-261. 2011.

6. Castillo C, Mira J, Suárez A. Presencia de obstrucción recurrente de las vías aéreas en un grupo de caballos criollos colombianos con signología respiratoria. Revista de Medicina Veterinaria, 26: 37-45. 2013.

7. Davidson E, Martin B. Diagnosis of upper respiratory tract diseases in the performance horse. The veterinary clinics of North America: equine practice, 19 (1): 51-62. 2003.

8. Dos Santos N, Da Graça D. Citologia do lavado broncoalveolar de eqüinos da Polícia Militar do Distrito Federal. Braz. J. vet. Res. anim. Sci., São Paulo, 44 (4): 268-274. 2007.

9. Engels $P$, Bagshaw $S$, Maier M, Brindley $P$. Traqueostomía: desde la inserción a la decanulación. Can J Surg, 52 (5): 427-433. 2009.

10. Flórez J. Evaluación citológica comparativa de lavajes traqueobronquiales realizados en caballos de salto sometidos a diferentes exigencias deportivas. Tesina Esp. Medicina deportiva del equino. Facultad de Ciencias Veterinaria, Universidad de Buenos Aires. Argentina. 67 p. 2013.

11. Hackett R. The significance of arytenoid cartilagent movement. En: Robinson $N(e d)$, Current Therapy in Equine Medicine $3^{\text {rd }}$ Ed. Philadelphia, Saunders, 285 p. 1992.

12. Haynes P. Larynix. En: Traub-Dargatz JL, Brown CM (eds): Equine endoscopy. St Louis, Mosby, Capítulo 6, 59 p. 1990.

13. Hewson J, Viel L. Sampling, microbiology and cytology of the respiratory tract. En: Lekeux P. (Ed.). Equine Respiratory Diseases, Saunders, St. Louis. 2002.

14. Hodgson J, Hodgson D. Collection and analysis of respiratory tract samples. En: McGorum B, Dixon P, Robinson N y Schumacher J, (Eds.), Equine Respiratory Medicine and Surgery, Saunders, Philadelphia, p 119-150. 2007.

15. Hodgson J, Hodgson D. Tracheal aspirates: indications, technique and interpretation. En: Robinson N (Ed.). Current Therapy in Equine Medicine, $5^{\mathrm{a}}$ ed. St. Louis: Saunders, p 401-406. 2003.

16. Hoffman A. Clinical application of pulmonary fuction testing in horses. En: Equine Respiratory Disease, Ed: Lekeux P. Publisher: International Veterinary Information. Service, Ithaca, New York, USA, 2002.

17. Hoffman A. Bronchoalveolar lavage: sampling technique and guidelines for cytologic preparation and interpretation. Veterinary Clinics of North America: Equine Practice, 24 (2): 423-435. 2008.

18. Larson V, Busch R. Equine tracheobronchial lavage: comparision of lavage cytologic and pulmonary histopatologic findings, Am J Vet Res, 46 (1): 144146. 1985.

19. Mair T, Stokes C, Bourne F. Cellular content of secretions obtained by lavage from different levels of the equine respiratory tract. Equine Vet J., 19 (5): 458462. 1987. 
20. Mansmann R, Knight $\mathrm{H}$. Tracheal aspiration in the horse. Journal American Veterinary Medical Association, 160 (11): 1527-1529. 1972.

21. Michelotto P, Biava J, Gonçalves R, Cassou F, Bonfá A, Machado C. Aspirado traqueal de cavalos clinicamente sadios da raça quarto de milha após prova de três tambores. Archives of Veterinary Science, 12 (2): 1-7. 2007.

22. Moran G, Araya O. Hemorragia pulmonar inducida por el ejercicio en el caballo: una revisión. Arch. Med. Vet., 35 (2): 127-138. 2003.

23. Pereira J, Moreira K, Abreu M, Paula C, Yukio D, Barroso D. Ocorrência de hemorragia pulmonar induzida pelo exercício em cavalos de pólo na cidade do Rio de Janeiro/RJ. Archives of Veterinary Science, 19 (2): 46-51. 2014.

24. Perrone G, Caviglia J, Pérez A, Fidanza M, Marquez A, Catelli J, González G. Cambios en las variables fisiológicas en equinos compitiendo en una prueba combinada. An. Vet. (Murcia), 22: 35-42. 2006.

25. Pollock $P$, Reardon R, Parkin T, Johnston M, Tate J, Love S. Dynamic respiratory endoscopy in 67 Thoroughbred racehorses training under normal ridden exercise conditions. Equine vet J., 41 (4): 354-360. 2009.

26. Reed S, Bayly W. Equine internal medicine. $3^{\text {rd }}$ ed. St. Louis: Saunders, 1466 p. 2010.

27. Santos L, Michelotto P, Kozemjakin D. Achados endoscópico e citológico das vias respiratórias de potros puro sangue inglês em início de treinamento no Jóquei Clube do Paraná. Arq. Ciênc. Vet. Zool. Unipar, Umuarama, 10 (1): 9 13. 2007.

28. Semeco E, Rodríguez M, Básalo A, Aranguren J, Fernández M. Prevalencia de las enfermedades obstructivas del tracto respiratório superior em equinos puirasangre de carreras. Revista Cientifica, 21 (3): 215-223. 2011.

29. Speirs V. Examen clínico de equinos. Porto Alegre: Ed Artes médicas, 366 p. 1999.

30. Souza N, Vasconcelos M, Fernandes P, Cordeiro H. Analysis of tracheal secretion in healthy horses undergoing a vaquejada simulation test. Open Journal of Veterinary Medicine, 4 (10): 232-238. 2014.

31. Sweeney C, Humber K, Roby K. Citologyc findings of tracheobronquial aspirates from 66 thoroughbred racehorses. Am J Vet Res, 53 (7): 1172-1175. 1992.

32. Viel L, Hewson J. BAL cytology in horses with exercise tolerance: what does it tell us? En: Proceedings of the $2^{\text {nd }}$ World Equine Airways Symp and $19^{\text {th }}$ Comp Respir Soc Meet, CD-ROM: 1-13. 2001.

33. Wilfong D, Waldridge B. Technical procedures. En: Reeder D, Miller S, Wilfong $D$, Leitch $M$ y Zimmel $D$ (Eds.), American association of equine veterinary technicians and assistans. Equine manual for veterinary technicians. Ames, lowa: Wiley- Blackwell. p 305-310. 2009. 